\title{
Plio-Pleistocene aardvarks (Mammalia, Tubulidentata) from East Africa
}

Thomas Lehmann

Museum für Naturkunde der Humboldt Universität zu Berlin, Invalidenstraße 43, 10115 Berlin, Germany. E-mail: thomas.lehmann@museum.hu-berlin.de, bibintom@gmail.com

Received 3 December 2007

Accepted 31 January 2008

Published 1 August 2008

\section{Key Words}

Chad

Ethiopia

Kenya

Pliocene

Pleistocene

Orycteropus crassidens

Orycteropus djourabensis

\begin{abstract}
The Tubulidentata are unique among mammals for being the only order represented nowadays by a single living species, Orycteropus afer: the aardvark. Nevertheless, it is one of the least studied mammalian orders. Aardvarks are currently distributed all over sub-Saharan Africa, but the fossil record extends their spatial range to Europe and Asia. The earliest known Tubulidentata are ca. 20 million years old. About 14 species and three to four genera have been recognised so far, but since the late Pliocene, aardvarks have only been represented by a single genus and are restricted to Africa. The extant aardvark is the only species of Tubulidentata with a large distribution area, i.e. the African continent. There are three known Plio-Pleistocene African species of aardvark: Orycteropus afer (Pallas, 1766), O. crassidens MacInnes, 1956, and O. djourabensis Lehmann et al., 2004. Fossils of these species have been discovered in North-Africa, Kenya, and Chad respectively. The present study is focused on the aardvark material found in the Plio-Pleistocene of East Africa (Ethiopia, Kenya). New specimens from Asa Issie (Ethiopia) and East Turkana (Kenya) are described, and published ones are re-examined in the light of the latest discoveries. This study demonstrates that Kenyan specimens identified as $O$.crassidens are in fact representatives of the Chadian O. djourabensis. Moreover, additional material from Ethiopia and Kenya shows a close relationship with the latter species too. The presence of specimens of $O$. djourabensis in Chad and in Kenya during the Plio-Pleistocene implies that this taxon is the oldestknown species of aardvark to have experienced a continental dispersal. It also shows that Tubulidentates were able to cross Africa from east-west during Plio-Pleistocene times, despite the presence of the Rift Valley. It is however not possible to infer the centre of origin of $O$. djourabensis. Finally, this study suggests that two species of aardvark might have co-existed in Kenya during the early Pleistocene.
\end{abstract}

\section{Introduction}

The Tubulidentata is one of the least studied orders of mammal. It is also the only mammalian order to be represented today by a single living species: Orycteropus afer (Pallas, 1766), the aardvark. This animal is nocturnal, fossorial, and feeds on ants and termites (myrmecophagous). It is currently distributed all over Africa south of the Sahara. Aardvarks can be found in a wide range of environments, from savannah to evergreen forests; it avoids, however, deserts. Fossil Tubulidentata have been recorded since ca. $20 \mathrm{Ma}$ in
Africa, and ca. $15 \mathrm{Ma}$ in Eurasia where they have completely disappeared nowadays (for a conspectus, see Lehmann 2006a, 2007). The biodiversity of the order was greater in the past with an acme during the late Miocene (Lehmann 2006a). About 14 species and three to four genera have been identified for the 20 myrs of their fossil record known so far. Since the Mio-Pliocene boundary however, the biodiversity of the order has been reduced to a single genus, restricted to Africa. The only exception is an isolated cranium of $O$. depereti Helbing, 1933 from the early Pliocene of France. 
When looking more carefully at the fossil record since the late Miocene, the co-occurrence of fossil Tubulidentata and early hominids is striking. For instance, they are both present in Aramis, Ileret, Koobi Fora, Laetoli, Lukeino, Swartkrans, and Toros-Menalla (Lehmann 2006b). Moreover, since the late Miocene a great geological formation - the Rift Valley - separates the eastern side of Africa from the rest of the continent. However, related taxa, like hippos, rhinos, elephants, suids, and even early hominids have been found on both sides of the Rift (e.g. Brunet et al. 1998, 2002) showing that it did not form an ecological barrier (contra Kortlandt 1972; Coppens 1983, 1994). The poorly known fossil aardvarks have never been investigated in this framework. Moreover, recent discoveries have enabled a review of our knowledge about Tubulidentata (e.g. Lehmann et al. 2004, 2005, 2006; Lehmann in press). That is why, the Plio-Pleistocene distribution of fossil aardvarks is investigated here. In particular, the African aardvark material discovered east and west of the Rift Valley is considered and compared.

\section{Material}

The studied material includes the extant species $O$. afer as well as the published fossil aardvark specimens of O. crassidens MacInnes, 1956 and O. djourabensis Lehmann et al., 2004. Moreover, new fossils from Ethiopia and Kenya are also described. All taxonomical information (spelling, author, date of publication, etc.) follows the comprehensive work of Lehmann (2007).

In order to perform a comprehensive comparative analysis, this study benefits from one of the largest extant aardvark database, as already used by Lehmann et al. (2004). It consists of over 100 specimens scattered in different international institutions: the American Museum of Natural History, New York (AMNH); the Archaeozoological Collection, Transvaal Museum, Pretoria; the Bernard Price Institute, Witwatersrand University, Johannesburg; the Staatliches Naturhistorisches Museum, Stuttgart; and the Museum für Naturkunde, Berlin.

The published fossil material re-examined for this study includes the holotype of $O$. crassidens MacInnes, 1956, an sub-complete adult skeleton (former field number Rusinga Island 1811'50, now NHM M 21543 to 21569) and the paratype, a partial skeleton of an adult individual (field number Kanjera 1-1955, including NHM M 15412). Both specimens are housed at the Natural History Museum (NHM), in London. The material added by Pickford (1975) is held in the National Museums of Kenya (KNM), in Nairobi. These specimens consist of a fragment of ulna (KNM-ER 875), a sub-complete skeleton (KNM-ER 876), and the partial skeleton of a juvenile aardvark, probably associated with the former one (KNM-ER 877). The holotype and only known specimen of O. djourabensis (KL09-98-001) has been described in an earlier paper by the present author (Lehmann et al. 2004). The repository of this subcomplete adult skeleton is the Centre National d'Appui à la Recherche (CNAR), in N'Djaména.

New fossil records are added to the present study. On the one hand, Kenyan specimens found in the East Turkana (formerly East Rudolf) and housed at the KNM. Fragments of a mandible (KNM-ER 44513) and elements of a hind limb (KNM-ER 40422) have been found at the Pleistocene site 11 of Koobi Fora (most probably not found in association), whereas scarce elements of a skeleton (KNM-ER 18855) have been found in the early Pliocene site 250 of Koobi Fora. On the other hand, specimens originating from Asa Issie, an early Pliocene site from Ethiopia (see White et al. 2006). They consist of isolated molars (ASI-VP-02/22, ASI-VP-02/23, and ASI-VP-02/272), a fragment of mandible with molar tooth row (ASI-VP-02/276), and a putative fragment of cranial roof (ASI-VP-05/04). This material is housed at the National Museum of Ethiopia in Addis Ababa.

\section{Comments on the three African Plio-Pleistocene species of aardvark}

It appears from the literature that the only species of Tubulidentata to show a continental distribution is the living species, O. afer. However, the fossil record for this species is very limited beyond the Palaeolithic ( $3 \mathrm{Ma}$ to $12 \mathrm{ka}$ ), and cannot help us to infer when and how this species really spread. Noticeably however, Pickford (2005) suggested that the early Pliocene material from Langebaanweg (South Africa) was the oldest fossil record for O. afer. Conversely, Lehmann (2006c; in press) found it impossible to determine on the basis of the known specimens, whether the Langebaanweg material as a whole belongs to $O$. afer or to O. crassidens. As a result, I recommend maintaining the tentative determination made by Hendey (1973) - O. cf. afer - until further material is discovered. Besides $O$. afer, there are two other species of Tubulidentata that lived during Plio-Pleistocene in Africa and that are considered here.

Orycteropus crassidens was first described from a sub-complete and a partial skeletons found in the Pleistocene of Rusinga Island and Kanjera respectively (Kenya; MacInnes 1956). No further material was added until the revision of the fossil Tubulidentata from East Africa by Pickford (1975). In fact, this author described three new specimens found in the East Turkana region (Koobi Fora and Ileret). Noticeably, Pickford (1975) relegated $O$. crassidens from its species level and considered that the holotype, the paratype, as well as the new material actually represented a sub-species: Orycteropus afer crassidens. Later on, he included all these fossils in Orycteropus afer without further distinction (Pickford 2005). However, the validity of the species $O$. crassidens has been discussed by other authors (e.g. Patterson 1978; Made 2003; Lehmann et al. 2005; Lehmann 2007, in press). Following Lehmann (2007; in press), the species $O$. crassidens is considered valid.

Orycteropus djourabensis was first described from Kollé (early Pliocene, Chad). Lehmann et al. (2004) compared the new species to $O$. afer and $O$. crassidens and emphasised the difficulties in identifying PlioPleistocene species on the basis of post-cranial elements or cranial remains alone. From their original description, the oblique orientation of the sockets for the upper teeth, the longer length of the lower tooth row, as well as the smaller hand distinguish O.djourabensis from $O$. crassidens. Interestingly, several humeri referred to $O$. crassidens (fragments from the holotype, more complete ones from the paratype and new material) have significantly different sizes. Taking into ac- 
count these information for their comparison of the Chadian aardvark, Lehmann et al. (2004: 207) decided that: "For the purpose of this article, only the holotype of O. crassidens [was] considered." Besides the complete humeri, this decision also precluded the authors taking into account the fragments of ulna only known from the paratype and the new material described by Pickford (1975). In the present study, all fossil material from $O$. crassidens and $O$. djourabensis has been re-examined. Special attention is given to the characters and dimensions of the humeri as well as the ulna of the material attributed to $O$. crassidens.

As reported by Lehmann (2007: tab. 2), many PlioPleistocene specimens of fossil aardvarks remain undetermined at the species level because of their scarcity or poor preservation. As illustrated for the Langebaanweg specimens (see above), considerable caution must be taken when identifying such fragmentary fossils. The new material, as well as the revised specimens, described in this paper are thus thoroughly compared to other species of Tubulidentata.

Remarks. The early Pliocene species $O$. depereti from France is known from a single cranium associated with a fauna correlated with MN15 (Rook \& Masini 1994). Moreover, according to Sen (1994) and Made (2003), this species shows close relationships to O. mauritanicus Arambourg, 1959 and O. gaudryi Major, 1888 respectively, two medium-sized Miocene Orycteropus species. Moreover, Lehmann (in press) includes these three species in a different genus. Considering this, and given the scarce comparative material to hand, this species is not further taken into account in the present study, inasmuch as the analysis will focus on the relationships between African Plio-Pleistocene Orycteropus.

\section{Systematic Palaeontology}

\author{
Order Tubulidentata Huxley, 1872 \\ Family Orycteropodidae Gray, 1821 \\ Subfamily Orycteropodinae Gray, 1821 \\ Genus Orycteropus Geoffroy, 1796
}

Type species. Orycteropus afer (Pallas, 1766).

\section{Orycteropus crassidens MacInnes, 1956}

1956 Orycteropus crassidens MacInnes: 28, figs 11, 12a, 13, pl. 3: fig. 4, pl. 4: fig. 7.

1975 Orycteropus afer crassidens. - Pickford: 76, fig. 6.

1975 Orycteropus afer crassidens. - Pickford: 76.

1978 Orycteropus crassidens. - Patterson: 273.

2003 Orycteropus crassidens. - Made: 140.

2005 Orycteropus afer. - Pickford: 274

2007 Orycteropus crassidens. - Lehmann: 184.

Holotype. Sub-complete skeleton housed at the NHM, London: partial skull (NHM M. 21543); left hemi-mandible (NHM M. 21544); right $\mathrm{M}_{2}$ (sectioned) (NHM M. 21545); right hemi-mandible (NHM M. 21546); atlas fragment (NHM M. 21547); axis (NHM M. 21548); $3^{\text {rd }}$ cervical vertebra (NHM M. 21549); $4^{\text {th }}$ cervical vertebra (NHM M. $21550) ; 5^{\text {th }}$ cervical vertebra (NHM M. 21551); $6^{\text {th }}$ cervical vertebra (NHM M. 21552); fragment of thoracic vertebra (probably $12^{\text {th }}$ following MacInnes (1956)) (NHM M. 21553); $8^{\text {th }}$ caudal vertebra (NHM M. 21554); $9^{\text {th }}$ caudal vertebra (NHM M. 21555); distal epiphysis of the left humerus (NHM M. 21556); distal fragment of the right humerus (NHM M. 21557); proximal epiphysis of the right radius (NHM M. 21558); right scaphoid (NHM M. 21559); right lunate (NHM M. 21560); left unciform (NHM M. 21561); proximal epiphyses of left metacarpals III \& IV (NHM M. 21562); articulation between metacarpal IV \& proximal phalanx IV (NHM M. 21563); proximal phalanx II, III \& intermediate phalanx II of the left hand as well as intermediate phalanx of the right hand (NHM M. 21564); distal phalanx III of the right hand (NHM M. 21565); left talus (NHM M. 21566); right metatarsal I (NHM M. 21567); proximal phalanx \& intermediate phalanx II of the left foot (NHM M. 21568); distal epiphysis of the right metacarpal II (NHM M. 21569).

Paratype. Partial skeleton (former field number Kanjera 1-1955) housed at the NHM, London: multiple fragments of skull; multiple fragments of mandible; scapula fragment; left and right complete humeri (NHM M. 15412); proximal fragment of right ulna; phalanges of the hands (except the right distal phalanx V \& the distal epiphysis of right proximal phalanx II); left metacarpals II \& V; right metacarpals III \& IV; carpals: scaphoids, trapezoids, left trapezium, fragments of the unciforms, right magnum, left lunate, fragment of the right pyramidal; lateral sesamoid bone for the M. gastrocnemius; intermediate and distal phalanges II of the right foot; intermediate and distal phalanges IV of the right foot; fragments of the fibular diaphysis; fragment of the proximal epiphysis of the tibio-fibula; patella.

Type Locality. Rusinga Island (Kiahera-Sienga area) $\left(0^{\circ} 26^{\prime} \mathrm{S}-34^{\circ} 9^{\prime} \mathrm{E}\right.$; Kenya) (Fig. 1).

Horizon. Pleistocene. MacInnes (1956) specified that the holotype has been found in a pocket of Pleistocene gravel and alluvium. The site where the paratype was found, Kanjera, is dated between 1.5 and 0.5 Ma (Behrensmeyer et al. 1995).

Discussion. As explained previously, Pickford (1975, 2005) added new material to the holotype and paratype, but relegated $O$. crassidens from its species level. Moreover, this author (1975: 81) suggested that the specimens belonging to this taxon "... form a group of Orycteropus close to O. afer both in size and postcranial morphology and are here classified as a subspecies of O. afer. [...] If O. a. crassidens were classified as a separate species from $O$. afer, the three lower Pleistocene partial skeletons from Rusinga [the holotype of O. crassidens, n.d.], Kanjera [the paratype of O.crassidens, n.d.], and East Rudolf [the additional material described by Pickford (1975), n.d.] would all have to be specifically separated, a view which seems to be extreme for deposits of closely comparable age." First, following Lehmann (2007, in press) the species O. crassidens is considered a valid one here. Second, the fossil aardvarks from Rusinga Island and Kanjera are actually distinct from the specimens from East Turkana (formerly East Rudolf). In the present paper, and in accordance with the new discoveries made since 1975, it is suggested that the latter fossils are representatives of the species $O$. djourabensis instead (see below). The species $O$. crassidens would thus be known exclusively from its holotype and paratype.

MacInnes (1956: 35) provisionally referred a distal phalanx (field number 1218'50 now labelled NHM 


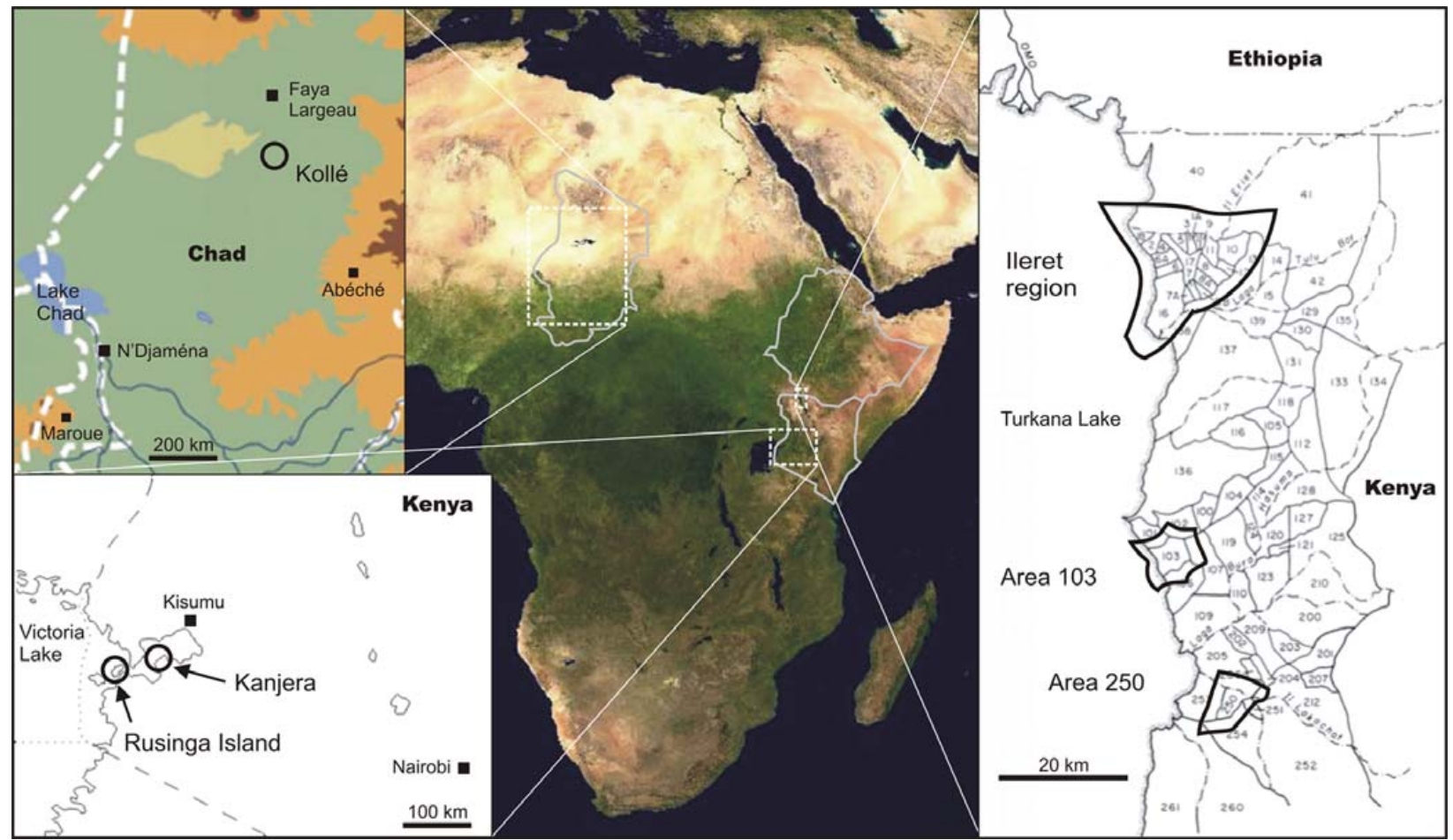

Figure 1. Fossil localities considered in this study. Right map modified after Brown \& Feibel (1991). This figure is available in colour online at museum-fossilrecord.wiley-vch.de

M 21570) to O. crassidens. Following Patterson (1975: 205), I consider that this specimen "may not be referable to the genus." Actually, this specimen may not be a Tubulidentata at all because it shows traces of a median crest on the proximal articular surface and lacks the typical heel on its proximo-palmar aspects. As a result, this fossil is withdrawn from the hypodigm of $O$. crassidens.

\section{Orycteropus djourabensis Lehmann et al., 2004}

1975 Orycteropus afer crassidens. - Pickford: 76.

2004 Orycteropus djourabensis Lehmann et al.: 202, figs 2-3, 5.

Holotype. Sub-complete skeleton in anatomical articulation (KL0998-001) housed at the CNAR, N'Djaména: skull and mandible with right $\mathrm{P}^{2}-\mathrm{M}^{3}$, left $\mathrm{M}^{1}-\mathrm{M}^{3}$, right $\mathrm{P}_{3}-\mathrm{M}_{3}$, and left $\mathrm{P}_{4}-\mathrm{M}_{3}$; fragment of the right scapula; elements of the vertebral column in anatomical connexion by sections (axis and five cervical vertebrae, 12 thoracic vertebrae, five lumbar vertebrae with sacrum and pelvis); complete fore limbs (except the left stylopode and some carpals); partial pelvis (acetabular region, fragments of ilion, ischion, and pubis); femur, tibio-fibula, tarsals, metatarsals, and phalanges of the right foot (including sesamoid bones); femur, tibia, tarsals, metatarsals, and phalanges of the left foot (including sesamoid bones).

Type Locality. KL09 site, Kollé $\left(16^{\circ} 20^{\prime} \mathrm{N}-19^{\circ} 00^{\prime} \mathrm{E}\right.$; Chad) (Fig. 1).
Horizon. Early Pliocene, 5-4 Ma (Brunet et al. 1998).

New material. All the new material comes from the East Turkana (formerly East Rudolf) area of Koobi Fora. The material consists of a incomplete ulna found in the Koobi Fora site 103 (KNM-ER 875) (Fig. 1). Moreover, there are two partial skeletons (one adult and one juvenile) found in the same gulley from the Ileret locality (Fig. 1). The elements of the two individuals have been mixed up and were certainly separated mainly on the basis of their size by Pickford (1975), and labelled accordingly. The adult partial skeleton (KNMER 876) is represented by: a complete left femur (A); the left tibial plateau $(\mathrm{AB})$; the proximal fragment of the left humerus (AC); the right metacarpal IV (AG); the right metatarsal $\mathrm{V}(\mathrm{AH})$; the proximal phalanx $\mathrm{V}$ of the left hand (AJ); the proximal phalanx $\mathrm{V}$ of the right hand (AK); a distal phalanx of the hand (AL); the left metacarpal II (AM); the left metacarpal V (AN); a distal fragment of the left metatarsal V (AO); a distal fragment of the right metatarsal V (AP); a fragment of the $1^{\text {st }}$ thoracic vertebra $(\mathrm{AQ})$; a fragment of lumbar vertebra $\left(2^{\text {nd }}\right.$ ?) $(\mathrm{AR})$; a fragment of lumbar vertebra (AS); a fragment of lumbar vertebra (AT); a fragment of cervical vertebra (AU); a fragment of the $3^{\text {rd }}$ cervical vertebra $(\mathrm{AV})$; a fragment of the $2^{\text {nd }}$ caudal vertebra $(\mathrm{AW})$; a fragment of caudal vertebra $\left(6^{\text {th }}\right.$ or $7^{\text {th }}$ ?) $(\mathrm{AX})$; a fragment of terminal caudal vertebra (AY); the incomplete right humerus (B); a diaphysis fragment of the left humerus (C); the proximal epiphysis of the left ulna (D); a distal fragment of the left tibia (E); a fragment of the left scapula (F); a fragment of the right acetabulum $(\mathrm{G})$; the distal epiphysis of the left radius $(\mathrm{H})$; a fragment of the right

Figure 2. Comparison of the mandibular articular surface in different Plio-Pleistocene Orycteropus. A. Left hemi-mandible of Orycteropus crassidens (NHM M. 21544) in lateral (figure reversed) (bottom) and occlusal (top) view. B. Left hemi-mandible of O. afer (AMNH 51372) in lateral view (figure reversed). C. Left hemi-mandible of O. afer (Coll. Univ. Poitiers) in occlusal view (figure reversed). D. Right hemi-mandible KNM-ER 876I in lateral (bottom) and occlusal (top) view. E. Left hemi-mandible of O. djourabensis (Holotype) in lateral (bottom) and occlusal (top) view. The incisura mandibulae is highlighted. This figure is available in colour online at museum-fossilrecord.wiley-vch.de 

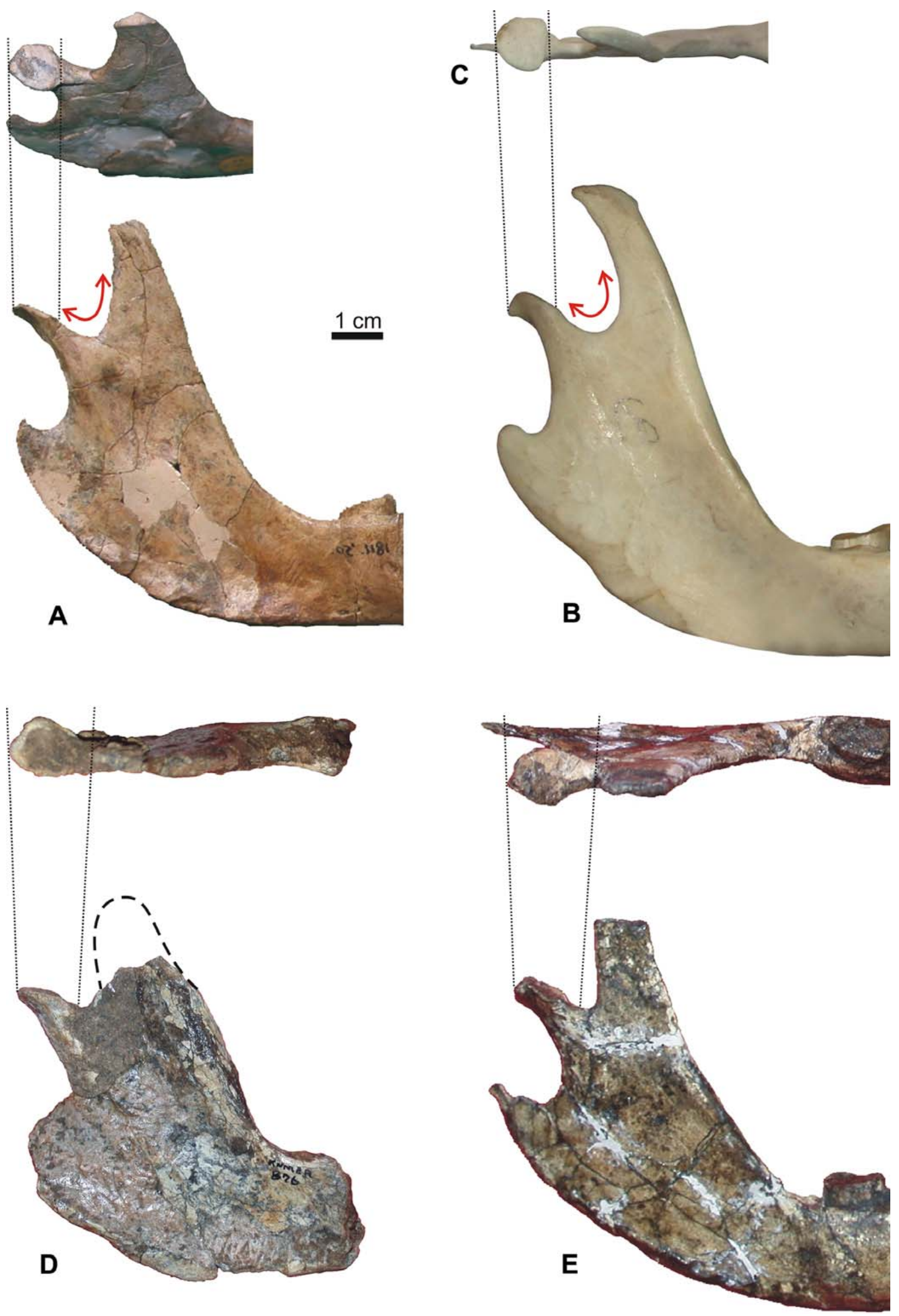
Table 1. Comparison of the dimensions (in $\mathrm{mm}$ ) of the mandible of some Tubulidentata species. $\mathbf{L M}_{1-3}$, length of the lower molar row; $\mathbf{B} @ \mathbf{M}_{2}$, corpus breadth at the $\mathbf{M}_{2}$ level; $\mathbf{H M}_{2-3}$, corpus height at the $\mathrm{M}_{2}-\mathrm{M}_{3}$ level. The data for $O$. crassidens and $O$. djourabensis are taken from the holotypes. Descriptive statistics: mean \pm standard deviation; number of observations indicated in brackets.

\begin{tabular}{llll}
\hline Species & $\mathbf{L M}_{\mathbf{1 - 3}}$ & $\mathbf{B} @ \mathbf{M}_{\mathbf{2}}$ & $\mathbf{H M}_{\mathbf{2 - 3}}$ \\
\hline Orycteropus afer & $\begin{array}{l}37.4 \pm 3.9 \\
(\mathrm{n}=63)\end{array}$ & $\begin{array}{l}12.7 \pm 1.6 \\
(\mathrm{n}=78)\end{array}$ & $\begin{array}{l}20 \pm 2.5 \\
(\mathrm{n}=78)\end{array}$ \\
O. crassidens & 43.3 & 13.9 & 22.5 \\
KNM-ER 44513 & 43 & 15 & - \\
O. djourabensis & 44.7 & 13.6 & 21.6 \\
KNM-ER 876 & 43 & 14.4 & 22 \\
ASI-VP-02/276 & - & 14 & 21.1 \\
\hline
\end{tabular}

mandible (ramus ascendens) (I); right calcaneum (J); the distal epiphysis of the left fibula (K); the left metatarsal III (L); the right metatarsal III (M); the right navicular $(\mathrm{N})$; the distal epiphysis of the left metacarpal III $(\mathrm{O})$; a proximal phalanx III of the hand $(\mathrm{P})$; a proximal phalanx III of the hand (Q); proximal phalanx IV of the hand (R); the intermediate phalanx $\mathrm{V}$ of the right hand $(\mathrm{S})$; a distal phalanx of the hand (T); and a distal phalanx V (U). Moreover, a partial left hemimandible bearing $\mathrm{P}_{3}-\mathrm{M}_{3}$ (current reference number KNM-ER 877A), considered as belonging to the juvenile skeleton by Pickford (1975), is herewith reintegrated into the adult one. The juvenile specimen (KNM-ER 877) is represented by: the distal half of the left humerus (B); the distal half of the right humerus (C); a fragment of the right scapula (D); and several indistinct fragments including parts of vertebrae and ribs (could also incorporate fragments of KNM-ER 876). Moreover, some elements attributed to the adult specimen show signs of immaturity and are herewith reintegrated into the juvenile one: the distal epiphysis of the right radius (current reference number KNM876AA); the distal epiphysis of the left metacarpal II (current reference number KNM-876AI).

Description of the new material. The two fragments of mandible bear important characters for identification of the Kenyan aardvark. For instance, the ascending ramus shows an angle with the corpus that is most probably inferior to $75^{\circ}$ (estimated angle as the corpus is not preserved). Such an angle is distinct from the Miocene African aardvarks like O. abundulafus and $O$. gaudryi and similar to the Plio-Pleistocene Orycteropus (see Lehmann et al. 2004, 2005). More interesting is the absence of a neck between the articular surface and the coronoid process on the mandible (absence of Incisura mandibulae) as in O. djourabensis (Fig. 2). In O. afer and O. crassidens, the articular condyle is separated from the coronoid process by a deep notch (and thus shows a kind of neck) that enables the passage of the N. massetericus, which innerves the M. masseter pars superficialis (Edge-

Table 2. Comparison of the dimensions (in $\mathrm{mm}$ ) of the teeth of some Tubulidentata species. L, mesio-distal length; B, maximum vestibulo-lingual breadth; $\mathbf{R}$, robustness index $(\mathrm{B} / \mathrm{L} \times 100) ; \mathbf{C L}_{\mathbf{M}}$, cumulative length of the lower molars; $\mathbf{C} \mathbf{L}^{\mathbf{M}}$, cumulative length of the upper molars. ${ }^{*}$ Estimated measurements. Other convention as in Table 1.

\begin{tabular}{|c|c|c|c|c|c|c|c|c|c|c|}
\hline \multirow[t]{2}{*}{ Lower teeth } & \multicolumn{3}{|l|}{$\mathrm{M}_{1}$} & \multicolumn{3}{|l|}{$M_{2}$} & \multicolumn{3}{|l|}{$M_{3}$} & \multirow[t]{2}{*}{$\mathrm{CL}_{\mathrm{M}}$} \\
\hline & $\mathrm{L}$ & B & $\mathrm{R}$ & $\mathrm{L}$ & $\mathrm{B}$ & $\mathrm{R}$ & $\mathrm{L}$ & $\mathrm{B}$ & $\mathrm{R}$ & \\
\hline O. afer & $\begin{array}{l}11.5 \pm 1.1 \\
(71)\end{array}$ & $\begin{array}{l}7.6 \pm 1.3 \\
(71)\end{array}$ & $\begin{array}{l}66.2 \% \pm 8 \\
(71)\end{array}$ & $\begin{array}{l}12.4 \pm 1.3 \\
(69)\end{array}$ & $\begin{array}{l}9 \pm 1.2 \\
(69)\end{array}$ & $\begin{array}{l}72.1 \% \pm 5.6 \\
(69)\end{array}$ & $\begin{array}{l}10 \pm 1.2 \\
(67)\end{array}$ & $\begin{array}{l}7.7 \pm 1 \\
(67)\end{array}$ & $\begin{array}{l}77.2 \% \pm 7.9 \\
(67)\end{array}$ & $\begin{array}{l}34 \pm 3 \\
(64)\end{array}$ \\
\hline $\begin{array}{l}\text { O. crassidens } \\
\text { (Holotype) }\end{array}$ & 13.1 & 8.8 & $67.2 \%$ & 14.3 & 10.6 & $74.1 \%$ & 12 & 8.9 & $74.2 \%$ & 39.4 \\
\hline $\begin{array}{l}\text { O. crassidens } \\
\text { (Paratype) }\end{array}$ & 14.6 & 8.9 & $61 \%$ & - & - & - & - & - & - & - \\
\hline KNM-ER 44513 & 14 & 9.1 & $65 \%$ & 14.3 & 10 & $69.6 \%$ & 11 & 9.1 & $82.7 \%$ & 39.3 \\
\hline $\begin{array}{l}\text { O. djourabensis } \\
\text { (Holotype) }\end{array}$ & 14.7 & 9 & $61.2 \%$ & 14.7 & 10 & $68 \%$ & 14.1 & 8.9 & $81.9 \%$ & 43.5 \\
\hline KNM-ER 876 & 14.8 & 9.4 & $63.5 \%$ & $15^{*}$ & $10^{*}$ & $66.7 \% *$ & 11.4 & - & - & $41.2^{*}$ \\
\hline ASI-VP-02/276 & - & - & - & 15.6 & 10.1 & $64.7 \%$ & 12.9 & 8.7 & $67.4 \%$ & - \\
\hline \multirow[t]{2}{*}{ Upper teeth } & \multicolumn{3}{|l|}{$M^{1}$} & \multicolumn{3}{|l|}{$M^{2}$} & \multicolumn{3}{|l|}{$M^{3}$} & \multirow[t]{2}{*}{$\mathrm{CL}^{\mathrm{M}}$} \\
\hline & $\mathrm{L}$ & B & $\mathrm{R}$ & $\mathrm{L}$ & $\mathrm{B}$ & $\mathrm{R}$ & $\mathrm{L}$ & $\mathrm{B}$ & $\mathrm{R}$ & \\
\hline O. afer & $\begin{array}{l}11.1 \pm 1.2 \\
(69)\end{array}$ & $\begin{array}{l}7.4 \pm 1.3 \\
(69)\end{array}$ & $\begin{array}{l}66.3 \% \pm 9 \\
(69)\end{array}$ & $\begin{array}{l}11.9 \pm 1.2 \\
(66)\end{array}$ & $\begin{array}{l}8.6 \pm 1 \\
(65)\end{array}$ & $\begin{array}{l}71.7 \% \pm 6 \\
(65)\end{array}$ & $\begin{array}{l}9.3 \pm 1.2 \\
(64)\end{array}$ & $\begin{array}{l}7.3 \pm 0.9 \\
(64)\end{array}$ & $\begin{array}{l}78.5 \% \pm 7.8 \\
(64)\end{array}$ & $\begin{array}{l}32.4 \pm 2.6 \\
(64)\end{array}$ \\
\hline $\begin{array}{l}\text { O. crassidens } \\
\text { (Holotype) }\end{array}$ & 11.9 & 9 & $75.6 \%$ & 13.7 & 10.2 & $74.5 \%$ & 11.1 & 8.7 & $78.4 \%$ & 36.7 \\
\hline $\begin{array}{l}\text { O. crassidens } \\
\text { (Paratype) }\end{array}$ & 13.9 & 9.3 & $66.9 \%$ & 13.7 & 9.9 & $72.3 \%$ & 10.7 & 8.8 & $82.2 \%$ & 38.3 \\
\hline $\begin{array}{l}\text { O. djourabensis } \\
\text { (Holotype) }\end{array}$ & 12.8 & 8.5 & $66.4 \%$ & 13.6 & 9.9 & $72.8 \%$ & 11.6 & 9.5 & $81.9 \%$ & 38 \\
\hline ASI-VP-02/276 & - & - & - & 14.4 & 9.3 & $64.6 \%$ & 10.6 & 8.2 & $77.4 \%$ & - \\
\hline
\end{tabular}


worth, 1924). The left corpus shows large dimensions, especially the length of the molar row, that are close to $O$. crassidens and O.djourabensis (Tab. 1). It bears moreover three weathered molars for which essentially only estimated measurements could be taken. The molars are bilobed and show a worn occlusal surface confirming that this element (formerly KNM-ER 877A) belongs to an adult individual and not a juvenile. These teeth are among the largest of the comparative sample and are significantly distinct from the teeth of O. afer (Tab. 2). For instance, the cumulative molar length is only dwarfed by the holotype of $O$. djourabensis. Comparable as much with $O$. crassidens as with $O$.djourabensis, the dental material of these Kenyan specimens is not sufficient for a reliable identification.

The forelimb elements of the Kenyan specimens include fragments of glenoid cavities of a right and left scapula. They do not bear any remarkable features although one distinctly belongs to a juvenile individual (KNM-ER 877D). More informative are the four humeri provided by the Kenyan specimens. Indeed, the humeri of $O$. djourabensis are relatively well-preserved, but the present material is in an even better condition, especially KNM-ER 876B (Fig. 3). The proximal epiphysis of these humeri is typical of the Orycteropodidae, with two salient tuberosities and a rounded general shape. The well-developed deltoid crest projects laterally, unlike in the late Miocene O. abundulafus and Leptorycteropus (see Lehmann et al. 2005). Likewise, the pectoral crest is marked and joins the deltoid crest upon the V-shaped deltoid tuberosity. Distally, the brachial crest is large and traces an oval and proximally bounded olecranon fossa. This feature is typical of the Plio-Pleistocene Orycteropus and distinguishes these taxa from the middle to late Miocene aardvarks.

The dimensions of the Kenyan material published by Pickford (1975) are, as noted above, confusing. Therefore, all measurements have been retaken in this study (Tab. 3). MacInnes (1956) published a distal breadth for the paratype of $O$. crassidens of $64.5 \mathrm{~mm}(63.5 \mathrm{~mm}$ in this study; DMB, Tab. 2), which is large but still within the range of variation of the extant aardvark. Conversely, O.djourabensis from Chad has a significantly more slender distal epiphysis. Pickford (1975: tab. VIII) gave the dimensions of the two best preserved additional specimens from Kenya, in particular their distal breadth: $41.4 \mathrm{~mm}$ (KNM-ER 876B) and $32.5 \mathrm{~mm}$ (KNM-ER 877B). These distal breadths are significantly different from the one measured for O. crassidens and close to that of $O$. djourabensis. Besides, as shown in Fig. 3, it is not possible to take such a measurements on the specified material. In fact, the accessible measurements (Tab. 3) show that the additional Kenyan humeri are relatively small compared to the Plio-Pleistocene Orycteropus. The length and breadth of these specimens are comparable to those of subadults of $O$. afer. To sum up, Fig. 4 illustrates that the adult humerus KNM-ER 876B (and thus the other additional Kenyan specimens as well) is 1) significantly

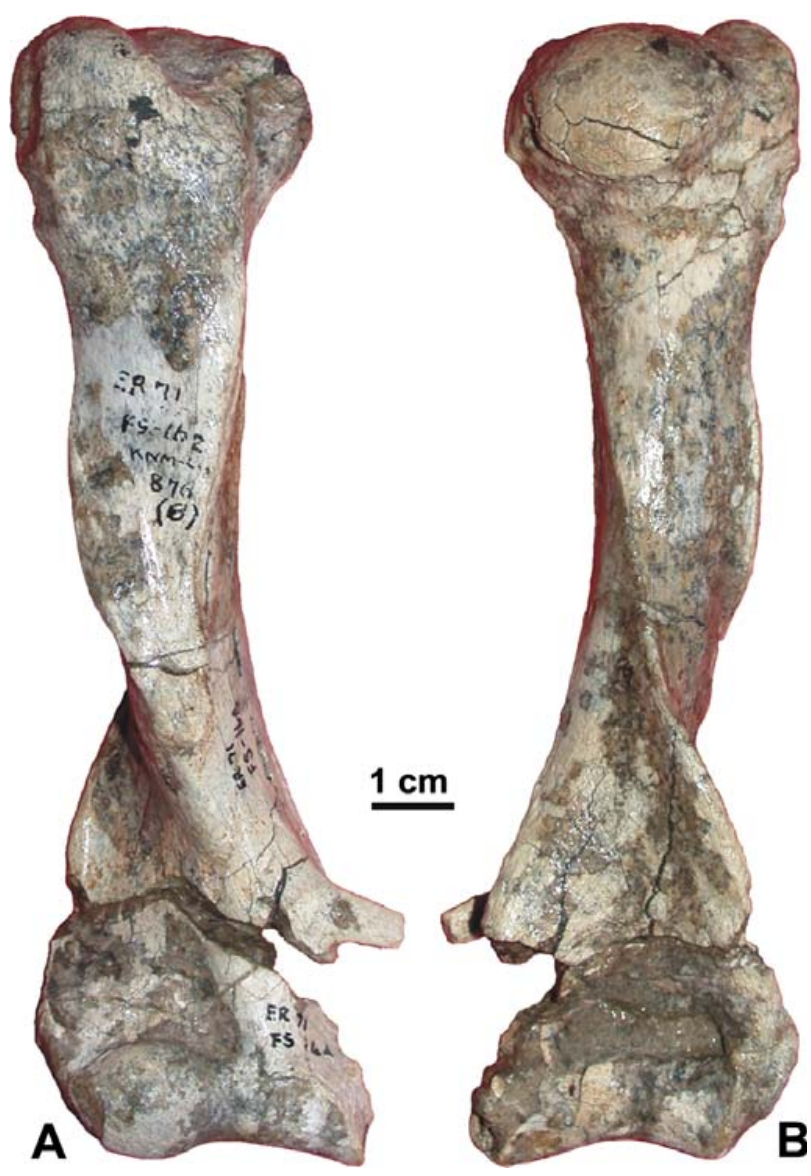

Figure 3. Right humerus of Orycteropus djourabensis KNMER 876B. A. Ventral view. B. Dorsal view. This figure is available in colour online at museum-fossilrecord.wiley-vch.de

smaller than its counterpart in $O$. crassidens; 2) significantly larger than the Miocene aardvarks; and 3) actually very close to $O$. djourabensis. Morphologically and biometrically, these humeri do not speak in favour of identify these specimens as $O$. crassidens.

Other elements of the forelimb, like the radii, are too weathered for analysis or, like the metacarpals and the phalanges, are broader but distinctly as short as in O. djourabensis. On the other hand, several ulnae provide, besides the typical Orycteropodidae morphology, an additional and very informative character: the medio-lateral orientation of the articulation axis of the trochlear notch with respect to the diaphysis of the ulna (Fig. 5). Within Plio-Pleistocene aardvarks, O. djourabensis is the only species known to present a mediolateral articulation axis oblique to the diaphysis. Conversely, in $O$. afer and $O$. crassidens this axis is more perpendicular and the articular surfaces of the notch do not face each other proximo-distally. In the latter configuration, "the pitch of these surfaces enlarges the contact with the distal epiphysis of the humerus and prevents uncontrolled movements and dislocation" (Lehmann et al. 2004: 208). Among the additional Kenyan material, KNM-ER 875 and KNM-ER 876D are the best-preserved ulnae with a complete trochlear notch. As shown in Fig. 5, these specimens display an oblique medio-lateral articulation axis for their trochlear notch. 


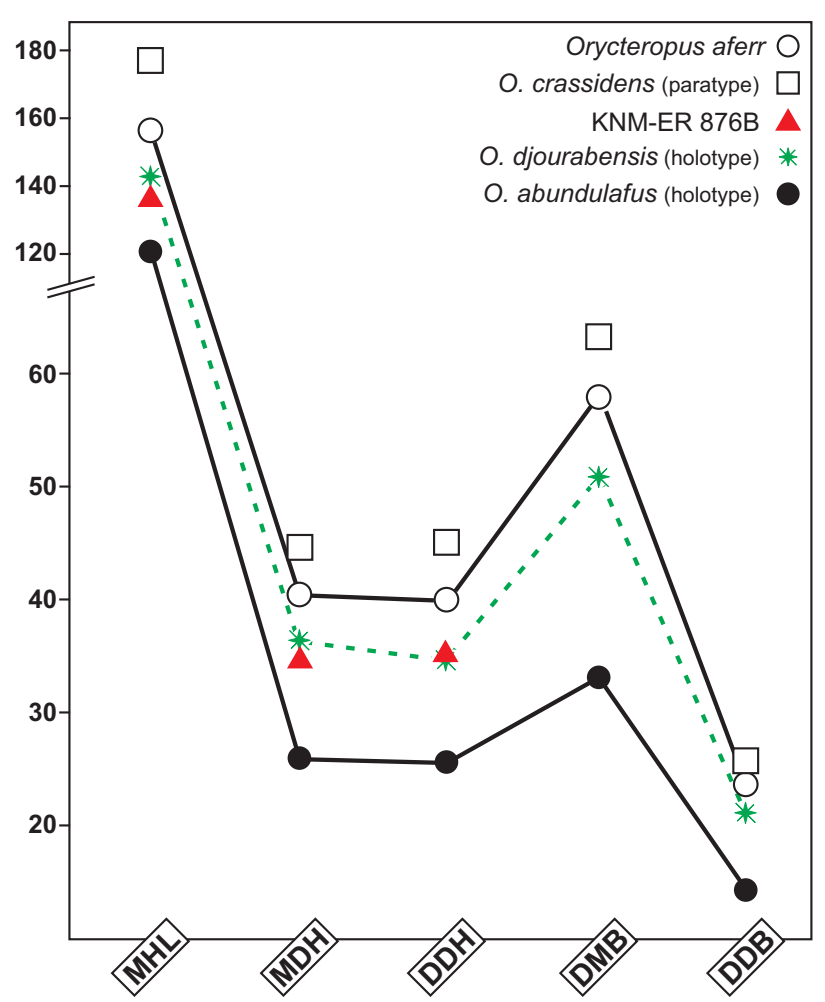

Figure 4. Graphical comparison of the dimensions (in $\mathrm{mm}$ ) of the humeri in some Tubulidentata. Legend as in Table 3. This figure is available in colour online at museum-fossilrecord.wiley-vch.de

They do not share the character state presented by $O$. crassidens but rather the one shown by $O$. djourabensis. The dimensions of the ulna are quite consistent between O.afer, O.crassidens, and O.djourabensis. Thus these ulnae of the additional material cannot be identified by their size. Nonetheless, it is interesting to note that the trochlear notch in these specimens is as broad but not as long proximodistally as in $O$. djourabensis.

Finally, several hind limb elements have been recovered along with these Kenyan specimens. The problem however, is that $O$. crassidens is mostly known from
Table 4. Comparison of the dimensions (in $\mathrm{mm}$ ) of the pelvis of some Tubulidentata species. AW, acetabulum proximodistal length; AH, acetabulum dorsoventral length. Other convention as in Table 1.

\begin{tabular}{lll}
\hline Espèce & AW & AH \\
\hline Orycteropus afer & $38.1 \pm 3.1(n=31)$ & $31.5 \pm 3.1(n=31)$ \\
KNM-ER 40422 & 34.7 & - \\
$\begin{array}{l}\text { O. djourabensis } \\
\text { (Holotype) }\end{array}$ & 32.7 & 27 \\
KNM-ER 876G & 34.8 & 25 \\
\hline
\end{tabular}

cranial and forelimb elements. Only a left talus, a metatarsal I, a proximal phalanx II, two proximal phalanges II and one IV, as well as two distal phalanges II and IV have been discovered so far, none of which is duplicated in the KNM-ER 875, 876, and 877 specimens. The acetabulum of the left coxal shows a size comparable to the small specimens of $O$. afer and close to O.djourabensis (Tab. 4). The left femur KNMER 876A presents the typical feature of all Orycteropodidae with a well developed great trochanter, a laterally projecting third trochanter, and the diagnostic pectineal tubercle (fourth trochanter) on the proximo-medial aspect of the diaphysis. The articular facet for the sesamoid bone, situated on the lateral distal condyle of the femur, is aligned with the diaphysis like in $O$. afer and O. djourabensis, and unlike that in O.gaudryi and O. abundulafus (see Lehmann et al. 2005). The dimensions of this element fall within the variation range of the extant aardvark (Tab. 5). This femur is longer than in the holotype of $O$. djourabensis but the other measurements are very close. Likewise, the distal epiphysis of the tibia KNM-ER 876E shows a size equivalent to the two Plio-Pleistocene Orycteropus (Tab. 6). The fragment of proximal epiphysis (AB) is however too damaged to distinguish any diagnostic characters or take measurements. Finally, as for the elements of the hand, the elements of the feet do not bear any features that

Table 3. Comparison of the dimensions (in $\mathrm{mm}$ ) of the humeri of some Tubulidentata species. MHL, maximum humerus length; MDH, mediolateral diameter of the head; DDH, dorsoventral diameter of the head; DMB, distal mediolateral breadth; DDB, distal dorsoventral breadth. Other convention as in Table 1.

\begin{tabular}{|c|c|c|c|c|c|}
\hline Species & MHL & $\mathrm{MDH}$ & $\mathrm{DDH}$ & DMB & DDB \\
\hline Orycteropus afer & $156.6 \pm 11.5(n=43)$ & $40.6 \pm 3(n=44)$ & $40 \pm 3(n=44)$ & $58.0 \pm 4.9(n=44)$ & $23.6 \pm 2.1(n=36)$ \\
\hline O. crassidens (Holotype) & - & - & - & - & 25.3 \\
\hline O. crassidens (Paratype) & 177.0 & 44.6 & 45.0 & 63.5 & 25.6 \\
\hline O. djourabensis (Holotype) & 142.7 & 36.4 & 34.8 & 51.0 & 21.2 \\
\hline KNM-ER 876 & 137 & 34.3 & 34.5 & - & - \\
\hline KNM-ER 877 & - & - & - & - & 21 \\
\hline O. abundulafus (Holotype) & 105.5 & 26.5 & 24.5 & 32.2 to 37 & - \\
\hline$($ TM255-03-01) & 105.6 & 26 & 25.6 & 33.2 & 14.5 \\
\hline O. gaudryi (AMNH 22762) & 121.0 & 30.3 & - & 40.9 & - \\
\hline
\end{tabular}



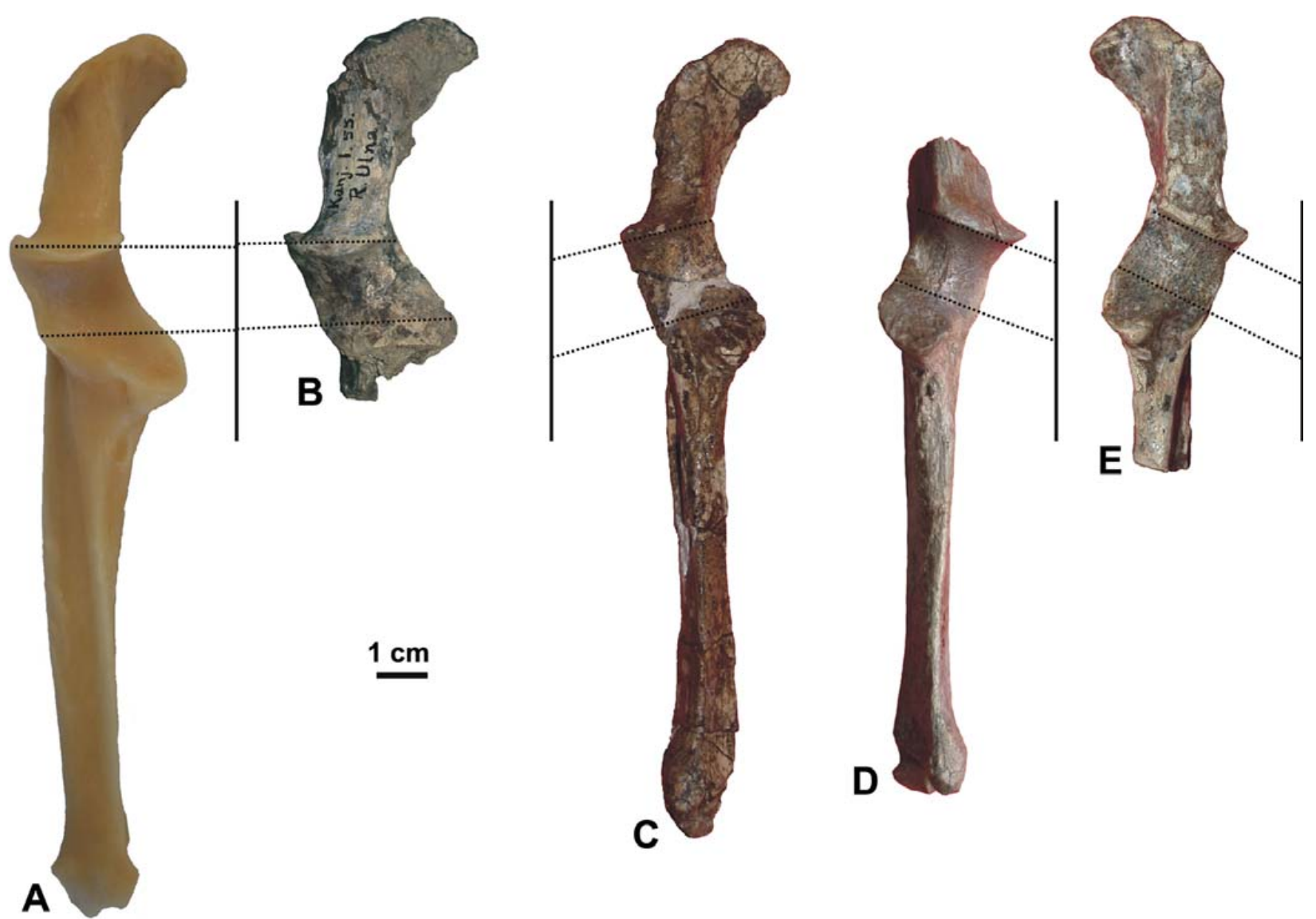

Figure 5. Comparison, in ventral view, of the medio-lateral orientation of the articular axis of the trochlear notch in different PlioPleistocene Orycteropus. A. Right ulna of Orycteropus afer (Coll. Univ. Poitiers). B. Right ulna of O. crassidens (NHM Kanjera 11955). C. Right ulna of $O$. djourabensis (holotype). D. Left ulna of KNM-ER 875. E. Left ulna of KNM-ER 876D. This figure is available in colour online at museum-fossilrecord.wiley-vch.de

differ from any of the Plio-Pleistocene Orycteropus. The size of these elements is relatively similar to that measured in O. afer, but tends to be very close to O. djourabensis (i.e. small), and also within the range of variation of the extant species.

Discussion. The specimens KNM-ER 875, 876, and 877 represent an aardvark form typical of the Plio-Pleistocene Orycteropus species, but is additionally characterised by large teeth and short forelimbs. These features are diagnostic of the Chadian O.djourabensis. Moreover, these Kenyan specimens, described by Pick- ford (1975) as "Orycteropus afer crassidens" and later (2005) as "Orycteropus afer", fail to show features diagnostic of the Rusinga Island and Kanjera species as well as of the extant species. In particular, the size of the teeth and the size of the forelimbs are significantly different between the Koobi Fora material and the species O. afer and O. crassidens. Conversely, the KNMER material shows for instance an articular facet of the mandible close to the coronoid process (absence of incisura mandibulae) and a medio-lateral articular axis of the sigmoid notch, which is oblique with respect to the diaphysis of the ulna, characters that are diagnostic of

Table 5. Comparison of the dimensions (in $\mathrm{mm}$ ) of the femora of some Tubulidentata species. MFL, maximum femur length; PMB, proximal mediolateral breath; DMB, distal mediolateral breadth; DAB, distal dorsoventral breadth. Other convention as in Table 1.

\begin{tabular}{lllll}
\hline Species & MFL & PMB & DMB & DAB \\
\hline Orycteropus afer & $193.9 \pm 17.1(n=43)$ & $67.7 \pm 7.4(n=43)$ & $58.3 \pm 4.7(n=43)$ & $58.1 \pm 4.3(n=40)$ \\
O. djourabensis (Holotype) & 177.4 & 63.3 & 52.9 & 54.2 \\
KNM-ER 876A & 188.6 & 63 & 55.5 & 54.2 \\
\hline O. gaudryi (AMNH 22762) & 142.2 & 44.5 & 41.4 & 39.9 \\
$\quad$ (AMNH 22888) & 136.6 & 43 & 37.5 & 35.2 \\
\hline
\end{tabular}


Table 6. Comparison of the dimensions (in $\mathrm{mm}$ ) of the tibia of some Tubulidentata species. DDB, distal dorsoventral breadth of tibia; DMB, distal mediolateral breadth of tibia. Other convention as in Table 1 .

\begin{tabular}{lll}
\hline Species & DDB & DMB \\
\hline Orycteropus afer & $28.6 \pm 3.4(28)$ & $38.5 \pm 4.3(16)$ \\
KNM-ER 40422 & 26.1 & 39 \\
O. djourabensis (Holotype) & 24.7 & 35.6 \\
KNM-ER 876E (estimated) & 25 & 39.1 \\
\hline
\end{tabular}

the Chadian $O$. djourabensis. As a result, I assign these three specimens here to the species $O$. djourabensis.

Considering that the new material added to $O$. djourabensis does not display duplicates of all elements present in the Chadian specimen, some original and unique features described for this species like the shallow lingual groove on the upper molars, the short diastema between the lower molars, the shallow angle between the rami of the mandible, or the presence of a continuous bony border between the tibial tuberosity and the proximal epiphysis of the fibula still remain to be confirmed on further material. Nonetheless, the rectification of the identification of the Kenyan material enables the proposal of the following new comparative diagnosis between the Chadian and Kenyan Plio-Pleistocene species. Orycteropus djourabensis differs from $O$. crassidens by: the oblique sockets for the upper teeth; the longer cumulative length of the lower molars; the absence of incisura mandibulae; the oblique orientation of the trochlear notch with respect to the diaphysis of the ulna; and the relatively smaller humerus and hand.

The fossiliferous sector of Kollé is biochronologically estimated to be around $4 \mathrm{Ma}$ old (Brunet et al. 1998, 2000). This early Pliocene sector is thus older than the Chadian Koro Toro one, which yielded Australopithecus bahrelghazali Brunet et al., 1995 and is younger than Toros-Menalla, the sector in which Sahelanthropus tchadensis Brunet et al., 2002 was found. So far, Kollé is the only Chadian site to contain specimens of $O$. djourabensis. The Kenyan specimens assigned to the latter species in the present study come from Pliocene and Pleistocene sites. Two specimens come from the Ileret region of Koobi Fora, which presents outcrops of the Okote and the Chari Members of the Koobi Fora Formation, dated geochronologically respectively between $1.56 \pm 05 \mathrm{Ma}$ and $1.38 \pm 0.03 \mathrm{Ma}$, and between $1.38 \pm 0.03 \mathrm{Ma}$ and $0.75 \pm 0.022 \mathrm{Ma}$ (McDougall \& Brown 2006). Their tag however (KNM-ER 876: ER 71 FS 16 Ileret 06A-1002/03; KNM-ER 877: ER 71 FS 15 Ileret 06A-1002/03), suggest that they have been found in the Area 6 (Lower Ileret Tuff, Okote Member) dated around $1.527 \pm 0.014 \mathrm{Ma}$ by McDougall \& Brown (2006). The third specimen (KNM-ER 875) has been found at the Koobi Fora site 103, in the Member E of the Shungura Formation, which is dated between 2.40 and 2.36 Ma (Bobe \& Behrensmeyer 2004). As a result, the stratigraphic range of the species $O$. djourabensis is extended from early Pliocene to the early Pleistocene (between 4 and $1.52 \mathrm{Ma}$ ). This taxon remains the oldest known African Plio-Pleistocene Orycteropus. Moreover, this temporal range now overlaps with that of indeterminate fossil aardvark specimens from South Africa and Tanzania (see Lehmann 2007: tab. 2), and does almost overlap with that of $O$. crassidens $(1.5-0.5 \mathrm{Ma})$ in Kenya. Given the scarce material of $O$. crassidens known so far, it is possible that both species were contemporaneous in Kenya during at least the early Pleistocene.

Remarks. The size of the teeth of KNM-ER 876, like these of $O$. djourabensis, does not show considerable differences compared to the teeth of $O$. crassidens, but still differs significantly from the dimensions measured in $O$. afer. It is the association of cranio-dental with postcranial features that enabled identification of this Plio-Pleistocene material (see Lehmann et al. 2004).

\section{Orycteropus sp. cf. djourabensis Lehmann et al., 2004}

Material. Isolated left $\mathrm{M}^{3}$ (ASI-VP-02/22); isolated right $\mathrm{M}^{2}$ (ASIVP-02/23); mesial lobe of a left $\mathrm{M}_{2}$ (ASI-VP-02/272); fragment of a left hemi-mandible bearing $\mathrm{M}_{1}$ to $\mathrm{M}_{3}$ (ASI-VP-02/276); putative fragment of cranial roof (Tubulidentata ?) (ASI-VP-05/04) housed at the National Museum of Ethiopia in Addis Ababa.

Locality. Asa Issie (Afar; Ethiopia) (see White et al. 2006: fig. 1)

Horizon. Localities ASI-VP-2 and ASI-VP-5 bear fossils in sediments correlated with the Sagantole Formation's Adgandole Member, and are dated more precisely between 4.1 and 4.2 Ma (White et al. 2006).

Description. The bulging fragments of cranial roof are hypothesised to represent part of the frontal and parietal bones along their common suture, but it is difficult to be certain even of their identification as an aardvark. The left hemi-mandible obviously belongs to an aardvark as it bears typical tubulidentate teeth (distal lobe of $\mathrm{M}_{1}$ and complete $\mathrm{M}_{2-3}$ ) (Fig. 6). The root of the as-
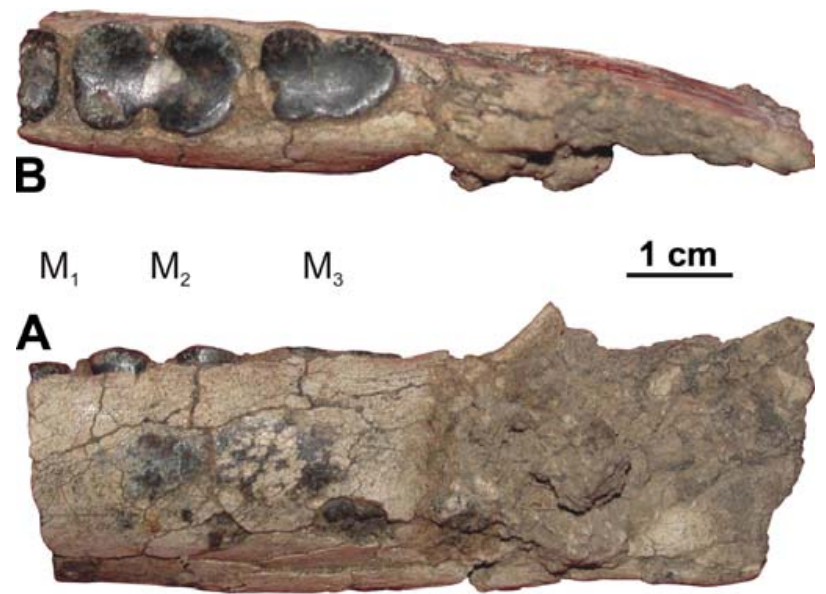

Figure 6. Left hemi-mandible of $O$. sp. cf. djourabensis ASIVP-02/276. A. Vestibular view. B. Occlusal view. This figure is available in colour online at museum-fossilrecord.wiley-vch.de 
cending ramus, behind the $\mathrm{M}_{3}$, is compressed and slightly deformed, but it still shows that the retromolar gap is relatively longer than in Miocene aardvarks. The few measurements taken show that this hemi-mandible compares with the largest specimens from the comparative sample (Tab. 1). All molars are bilobed and show a significantly larger size than in O. afer (Tab. 2). The dimensions of the $\mathrm{M}_{2}$ are among the highest in the sample, and are only comparable to $O$. djourabensis KNMER 876. On the other hand, the $\mathrm{M}_{3}$ is rather long but is close to its counterpart in O. djourarenbis and O. crassidens.

Two slightly weathered complete upper teeth are also preserved. The $\mathrm{M}^{2}$ is a large bilobed molar with a rectangular outline: it is the longest $\mathrm{M}^{2}$ in the comparative sample (Tab. 2). Although as broad as in the three other species, ASI-VP-02/23 is significantly distinct from $O$. afer and slightly longer than O. crassidens and O. djourabensis. Noticeably, the height of this tooth is laterally convex. The $\mathrm{M}^{3}$ is also bilobed and large but its size is not distinct from that in O. afer, O. crassidens, and O.djourabensis (Tab. 2). Again, this molar presents a lateral curvature on its height. This character is important as the upper molars in Tubulidentata are generally convex. However, MacInnes (1956: 30) noticed that in O.crassidens, "the socket [for the upper molars are] practically perpendicular to the plane of the palate" (Fig. 7). In this respect, Lehmann et al. (2004) suggested that there is a link between the shape of the upper teeth and the orientation of their alveoli relative to the palatine plane. It is probable that the upper teeth of most of the Orycteropodidae are curved as a result of the oblique orientation of their alveoli. Conversely, the upper teeth in $O$. crassidens are probably more vertical than in other Orycterodidae. As no isolated upper molars of $O$. crassidens are known so far, this character cannot be confirmed. Nonetheless, I suggest that the curvature observed in the Ethiopian aardvark distinguishes this morphotype from $O$. crassidens.

Discussion. The aardvark material discovered at Asa Issie is almost exclusively composed of dental elements. The large dimensions of the mandible and especially of the teeth clearly differ from those of their counterparts in O. afer. It is however more difficult to distinguish this form from $O$. crassidens and $O$. djourabensis without further material, like postcranial elements. However, the observed lateral curvature on the height of the upper molars would favour a closer relationship to $O$. djourabensis than to O. crassidens. Therefore, the Asa Issie aardvark is tentatively identified as Orycteropus sp. cf. djourabensis until further material is discovered.

\section{Orycteropus sp. indet., sample A}

Material. Partial left and right hemi-mandibles of the same individual (KNM-ER 44513), housed at the KNM, Nairobi (Fig. 8).

Locality. Area 11 from the Ileret locality, East Turkana (formerly East Rudolf; Kenya) (see Fig. 1).

Horizon. Okote Member of the Koobi Fora Formation, early Pleistocene, dated between $1.56 \pm 0.05$ and $1.38 \pm 0.03 \mathrm{Ma}$ (McDougall \& Brown 2006).

Description. The two hemi-mandibles are strongly weathered. The left one consists of a section of the corpus bearing $\mathrm{M}_{1}, \mathrm{M}_{2}$, and the mesial lobe of the $\mathrm{M}_{3}$. The right hemi-mandible shows a complete molar tooth row and the root of the ascending ramus. The dimensions of this mandible are large (Tab. 1). The length of the lower molars tooth row for instance is significantly longer than for the extant O. afer. Nonetheless, this length is close to that measured on the holotypes of $O$. crassidens and $O$. djourabensis. Likewise, the breadth of the mandible at the level of the $\mathrm{M}_{2}$ is closer to that of the two fossil taxa. The bilobed molars show a rectangular outline typical of all Plio-Pleistocene Orycteropus species. Their large dimensions significantly distinguish again KNM-ER 44513 from the specimens of O. afer (Tab. 2). Conversely, the molars cannot be distinguished from these of $O$.crassidens and $O$.djourabensis based on their size.

Discussion. The two hemi-mandibles described here belong to an Orycteropus specimen and are clearly distinct in terms of their size from O. afer. Conversely, there are not sufficient diagnostic characters to be able to discriminate KNM-ER 44513 either from O. crassidens or from $O$. djourabensis specimens. The systematic position could probably be refined using upper tooth row or postcranial elements. Consequently, this specimen remains tentatively unidentified at the species level.

Remarks. KNM-ER 44513 is kept in the same box as post-cranial material. This material does not belong to a Tubulidentata. Moreover, the same site yields hind

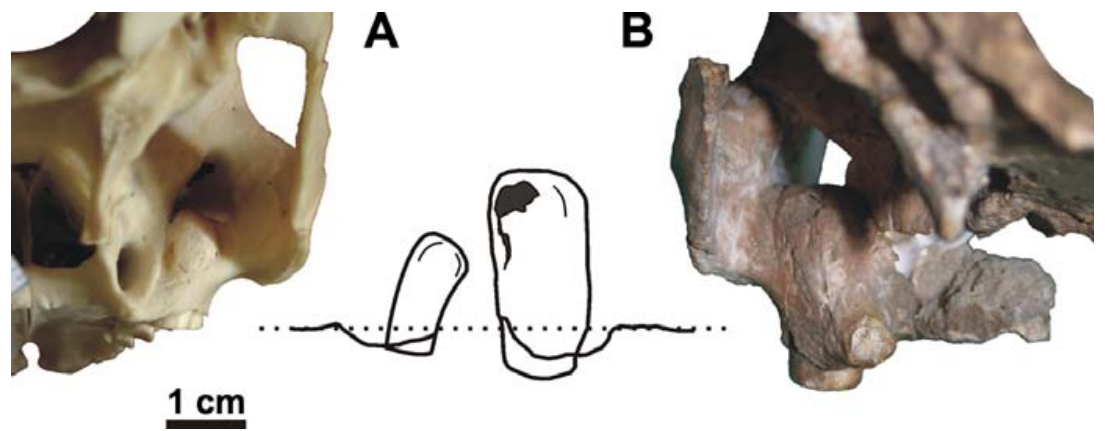

Figure 7. Comparison of the orientation of the upper dental alveoli in caudal view. A. Skull of Orycteropus afer (Coll. Univ. Poitiers). B. Skull of $O$. crassidens (holotype). This figure is available in colour online at museum-fossilrecord.wileyvch.de 

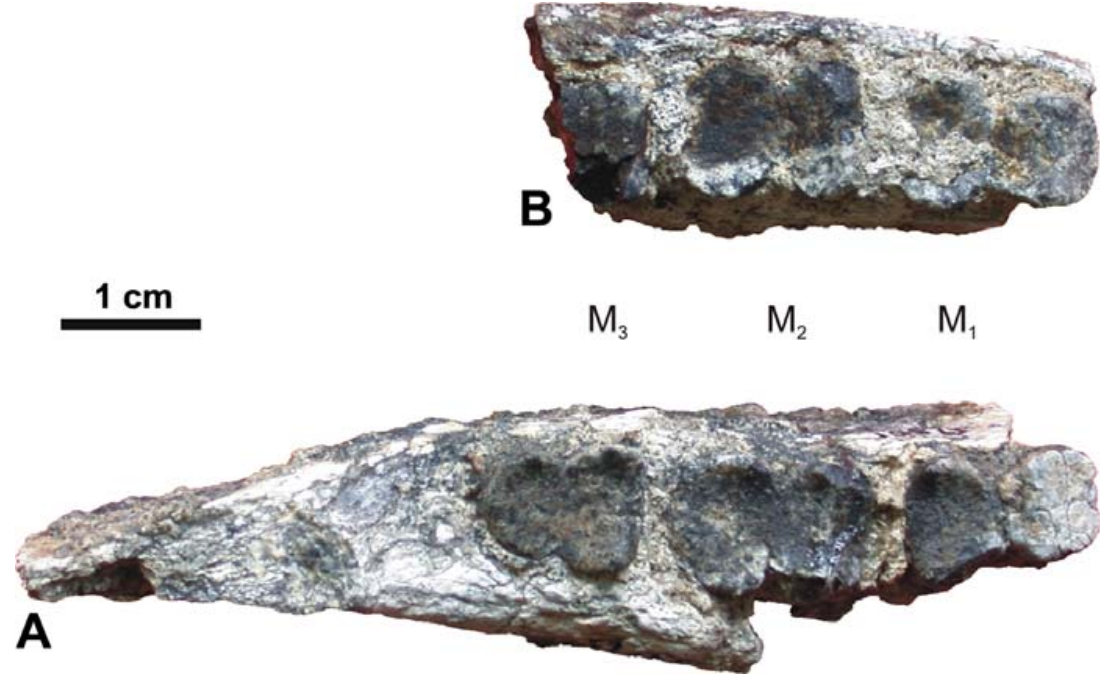

Figure 8. Occlusal view of Orycteropus sp. indet. KNM-ER 44513. A. Right hemi-mandible. B. Left hemi-mandible. This figure is available in colour online at museum-fossilrecord.wiley-vch.de limb elements of another aardvark (KNM-ER 40422). It is doubtful that they were both found in association, but the later specimen shows limbs slightly larger than in O. djourabensis (see below).

\section{Orycteropus sp. indet., sample B}

Material. Associated elements of the hind limb (KNM-ER 40422), housed at the KNM, Nairobi: fragments of pelvis; fragment of femoral diaphysis; left and right distal epiphyses, fragment of diaphysis, and right proximal epiphysis of tibio-fibula (Fig. 9); distal epiphysis of the right metatarsal II; both calcanei.

Locality. Area 11 from the Ileret locality, East Turkana (formerly East Rudolf; Kenya) (see Fig. 1).

Horizon. No specific indication of horizon. The Ileret region presents outcrops of the Okote and the Chari Members of the Koobi Fora Formation. It can thus be dated between $1.56 \pm 0.05 \mathrm{Ma}$ and $0.75 \pm 0.022 \mathrm{Ma}$ (McDougall \& Brown 2006).

Description. There exist no comparable elements in the hypodigm of $O$. crassidens. Among the fragments of pelvis, the preserved left acetabulum shows dimensions comparable to those in the small specimens of $O$. afer and to $O$. djourabensis (Tab. 4). The few preserved fragments of tibio-fibula show sizes comparable to their counterparts in $O$. afer and O.djourabensis, especially the distal epiphysis (Tab. 6). As recognized by Lehmann et al. (2004: 212), the proximal epiphysis of O. djourabensis shows "a continuous border, running from the tibial tuberosity to the junction with the fibula, and projecting dorsally over the insertion fossa for the Musculus tibialis anterior. As noticed by Patterson (1975), a deep notch replaces this border and opens the fossa on the proximal surface in O. afer." In KNMER 40422 (Fig. 9), the dorsolateral side of the proximal epiphysis of the tibia is damaged. The dorsal notch appears nonetheless less deep than in O. afer, such that the presence of a continuous bony border is possible. It is not clear from the superficially exposed cancellous bone if a falciform process similar to the one in $O$. afer and $O$. djourabensis was present. Note that the function of such a falciform process is unknown (MacPhee, 1994). The tarsal and metatarsal elements of KNMER 40422 do not depart from their counterpart in Orycteropus. Their size is however somewhat larger than in O. djourabensis and comparable with those in O. afer.

Discussion. From their size, these specimens are close to the extant species and are somewhat larger than in O. djourabensis. Conversely, the morphology of the proximal epiphysis of the tibia is closer to the latter species (shallow dorsal notch or even presence of a continuous border). The absence of a falciform process would be a unique feature among Plio-Pliocene aardvarks, although there is no known interpretable tibio-fibula for $O$. crassidens so far. The absence of cranial along with post-cranial data illustrates once again the difficulty in identifying Plio-Pleistocene aardvarks and justifies the tentative identification as Orycteropus sp.

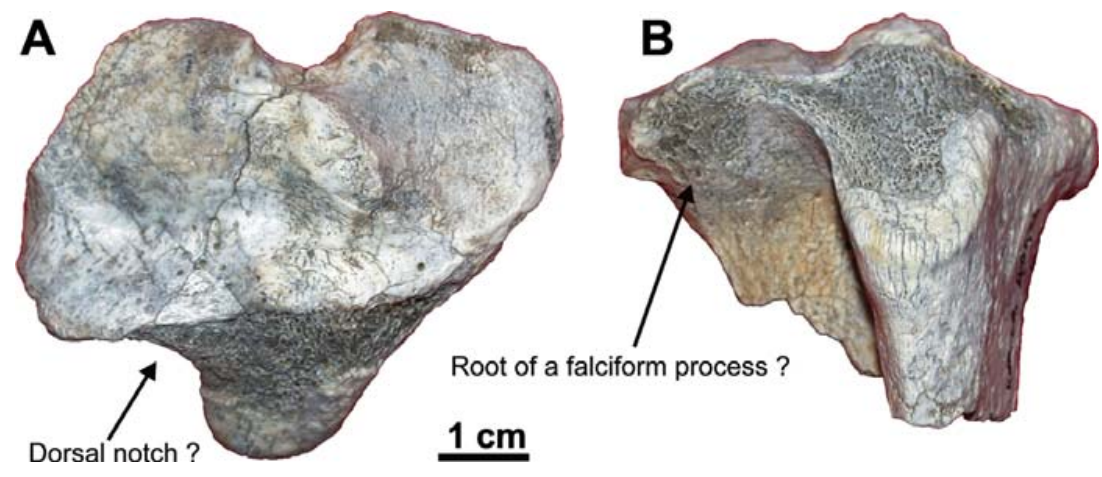

Figure 9. Proximal epiphysis of the right tibia of Orycteropus sp. indet. KNM-ER 40422. A. Proximal view. B. Dorsal view. This figure is available in colour online at museum-fossilrecord.wiley-vch.de 
Remarks. Two hemi-mandibles (KNM-ER 44513) have been found at the same site. They are unlikely to have been found associated with the present fossil. Noticeably, the former specimens have been kept as an indeterminate species, but are significantly distinct from O. afer.

\section{Orycteropus sp. indet., sample C}

Material. Elements of a skeleton (KNM-ER 18855), housed at the KNM, Nairobi: left and right talus (A \& B) (Fig. 10); left metacarpal III (C); and fragments of vertebrae and ribs.

Locality. East Turkana, Area 250 (Kenya) (see Fig. 1).

Horizon. No specific indication of horizon but the southern part of Koobi Fora, where Area 250 is situated, present outcrops of the Lonyumun, Moiti, and Lokochot Formations suggesting an early Pliocene age (between 4 and 3.4 Ma according to Brown \& Feibel 1991).

Description. Although shorter than in O. afer, O. crassidens, and O.djourabensis, the metacarpal III KNMER $18855 \mathrm{C}$ (41.5 $\mathrm{mm}$ in length) is morphologically similar to its counterpart in the three species. Conversely, the tali both fall within the range of variation of $O$. afer (Tab. 7). Their dimensions are larger than in O. djourabensis and smaller than in O. crassidens. Moreover, these tali show sub-equal mediolateral and proximodistal lengths $\left(\mathrm{L}_{2}\right.$ and $\mathrm{L}_{3}$; Tab. 5), a well-developed posteromedial process, and a concave cotylar facet for the medial malleolus of the tibia, as in all Plio-Pleistocene Orycteropus species. The head of the talus is round, as in $O$. afer and $O$. crassidens (sub-equal dimensions), but shows a rather dorsoventrally elongated articular surface as in $O$. djourabensis.

Discussion. The talus shows morphological characters and dimensions typical of the Plio-Pleistocene Orycteropus. However, a more precise identification is difficult as, in isolation, the elongation of the articular surface on the head of the talus might show a closer relationships with $O$. djourabensis, although the size of the talus in the latter species is apparently smaller. Moreover, the distinctly smaller size of the metacarpal reinforces the uncertainty. In conclusion, the absence of associated cranial and postcranial material again hin-
Table 7. Comparison of the dimensions (in $\mathrm{mm}$ ) of the talus of some Tubulidentata species. $\mathbf{L}_{\mathbf{1}}$, dorsoventral length; $\mathbf{L}_{\mathbf{2}}$, mediolateral length; $\mathbf{L}_{\mathbf{3}}$, proximodistal length. The data for $O$. crassidens and $O$. djourabensis are taken from the holotypes. Other convention as in Table 1.

\begin{tabular}{llll}
\hline Species & $\mathrm{L}_{1}$ & $\mathrm{~L}_{2}$ & $\mathrm{~L}_{3}$ \\
\hline Orycteropus afer & $26.6 \pm 2.3(18)$ & $38.3 \pm 3.2(20)$ & $38.2 \pm 3(21)$ \\
O. crassidens & 26.3 & 39.1 & 38.7 \\
KNM-ER 18855 & 24.9 & 36 & 35.9 \\
O. djourabensis & 21.6 & 33 & 34.4 \\
\hline
\end{tabular}

ders the identification of this form. Therefore, I recommend treating this specimen as an indeterminate taxon of the genus Orycteropus.

\section{Conclusions}

Since the early Miocene, 14 species of Tubulidentata have been described from Africa and Eurasia (see Lehman 2006). During the Plio-Pleistocene, only three species from a single genus are known in Africa, but their distribution was considered to be restricted. Only the extant $O$. afer was known to show a continental distribution but the first stages of its expansion are equivocal. The revision of the Kenyan specimens and the description of new material from Ethiopia and Kenya demonstrate, for the first time, that a fossil species was present at the same time in two distant regions of Africa: Chad on the one hand, and Ethiopia and Kenya on the other hand. O. djourabensis would thus be the oldest-known species of aardvark to have achieved a continental dispersal. The two regions where this species has been discovered are situated east and west of the Rift Valley. According to this analysis, the distribution of fossil Tubulidentata was not influenced by the Rift during Plio-Pleistocene times. As recognised for other mammals (see Brunet et al. 1998), passage between Central and East Africa was possible. It would seem, therefore, plausible that early hominids could also have crossed the Rift Valley during the Plio-Pleistocene and
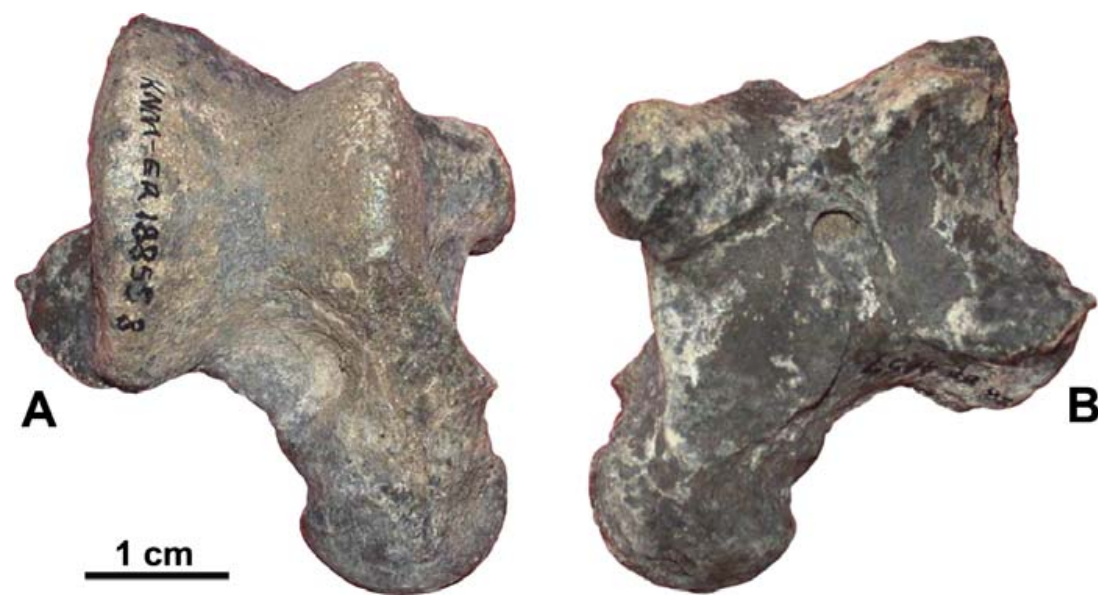

Figure 10. Orycteropus sp. indet. KNMER 18855B. Right talus. A. Dorsal view. B. Ventral view. This figure is available in colour online at museumfossilrecord.wiley-vch.de 
that the Rift was not the ecological and gene-flow barrier suggested by the "East Side Story" scenario (Kortlandt 1972; Coppens 1983, 1994).

The oldest unequivocal specimens of $O$. djourabensis known so far come from its type locality Kollé (Chad). The Ethiopian site, from which the new aardvark material referred to $O$. cf. djourabensis is described here, is penecontemporary to Kollé. It is thus not yet possible to infer whether the centre of origin of $O$. djourabensis was in Central or East Africa. In the latter region, and according to the present study, O.djourabensis coexisted with indeterminate fossil aardvark specimens (e.g. Leakey 1987) and perhaps even with $O$. crassidens during at least the early Pleistocene. These indeterminate specimens and further discoveries could help answering the question about the origin of $O$. djourabensis. In this respect, Lehmann et al. $(2004,2006)$ showed that the older Chadian O. abundulafus is not closely related to $O$. djourabensis, and is therefore certainly not ancestral to it. In South, Central and East Africa, several PlioPleistocene specimens show the same trend toward large teeth as shown in O.djourabensis and O. crassidens. This feature is not present in the extant aardvark and might prove to be an interesting character to study when looking for the ancestry of $O$. afer.

\section{Acknowledgements}

I would like to thank the heads and co-workers of the different institutions where the studied aardvark specimens are housed: in particular the Museum für Naturkunde, Berlin, the National Museum of Ethiopia, Addis Ababa, and the National Museums of Kenya, Nairobi. I express my sincere gratitude to $T$. $D$. White for inviting me to study the Asa Issie fossil aardvarks. Special thanks to B. Asfaw for his help during my 'eventful' stay in Addis Ababa, and to J. Dunlop for his help with the manuscript. T. L. acknowledges financial support from the RHOI project funded by the NSF. The NRF provided additional support via a postdoctoral fellowship at the Transvaal Museum, Pretoria. The last stage of this work was funded by a Humboldt Postdoctoral Research Fellowship at the Museum für Naturkunde, Berlin. The research presented in this paper benefited largely from the work of the MPFT (directed by M. Brunet) in the Djourab desert (Chad). Finally, I would like to thank T. Harrison and S. Sen for their comments that greatly improved the manuscript.

Special Note. Results of this research were presented in part as a poster at the "African Genesis Symposium of Human Evolution in Africa", Johannesburg, $8^{\text {th }}-14^{\text {th }}$ January 2006

\section{References}

Behrensmeyer, A. K., Potts, R., Plummer, T., Tauxe, L., Opdyke, N. \& Jorstad, T. 1995. The Pleistocene locality of Kanjera, Western Kenya: stratigraphy, chronology and paleoenvironments. - Journal of Human Evolution 29: 247-274.

Bobe, R. \& Behrensmeyer, A. K. 2004. The expansion of grassland ecosystems in Africa in relation to mammalian evolution and the origin of the genus Homo. - Palaeogeography, Palaeoclimatology, Palaeoecology 207: 399-420.

Brown, F. H. \& Feibel, C. S. 1991. Stratigraphy, depositional environments and paleogeography of the Koobi For a Formation. In Harris, J. M. (ed.). Koobi For a Research Project, Volume 3, Stratigra- phy, Artiodactyls and Paleoenvironments. Clarendon Press, Oxford: pp. 1-30.

Brunet, M., Beauvillain, A., Coppens, Y., Heintz, E., Moutaye, A. H.E. \& Pilbeam, D. 1995. The first Australopithecine 25000 kilometres west of the Rift Valley (Chad). - Nature 378: 273-274

Brunet, M., Beauvillain, A., Geraads, D., Guy, F., Kasser, M., Mackaye, H. T., Maclatchy, M. L., Mouchelin, G., Sudre, J. \& Vignaud, P. 1998. Tchad: un nouveau site à Hominidés Pliocène. - Comptes Rendus de l'Académie des Sciences, Paris 324 (2a): 341-345.

Brunet M. \& M. P. F. T. 2000. Chad: Discovery of a vertebrate Fauna close to Mio-Pliocene Boundary. - Journal of Vertebrate Paleontology 20 (1): 205-209.

Brunet, M., Guy, F., Pilbeam, D., Mackaye, H. T., Likius, A., Ahounta, D., Beauvillain, A., Blondel, C., Bocherens, H., Boisserie, J.-R., de Bonis, L., Coppens, Y., Dejax, J., Denys, C., Duringer, P., Eisenmann, V., Fanone, G., Fronty, P., Geraads, D., Lehmann, T., Lihoreau, F., Louchart., A., Mahamat, A., Merceron, G., Mouchelin, G., Otero, O., Campomanes, P. P., Ponce De Leon, M., Rage, J.-C., Sapanet, M., Schuster, M., Sudre, J., Tassy, P., Valentin, X., Vignaud P., Zazzo, A. \& Zollikofer, C. 2002. A new hominid from the Upper Miocene of Chad, Central Africa. - Nature 418: 145-151.

Coppens, Y. 1983. Le singe, l'Afrique et l'homme. Fayard, Paris.

Coppens, Y. 1994. East Side Story, the origin of Humankind. -Scientific American 270: 88-95.

Edgeworth, F. H. 1924. On the masticatory, intermandibular, and hyoid muscles of Orycteropus capensis. - Journal of Anatomy 58 134-139.

Hendey, Q. B. 1973. Fossil occurrences at Langebaanweg, Cape Province. - Nature 244: 13-14.

Kortlandt, A. 1972. New Perspectives on Ape and Human. Amsterdam, Stichting voor Psychobiologie.

Leakey, M. G. 1987. Fossil aardvarks from the Laetolil Beds. In Leakey M. D. \& Harris J. M. (eds). Laetoli, a Pliocene site in Northern Tanzania. Clarendon Press, Oxford: pp. 297-300.

Lehmann, T. 2006a. The biodiversity of the Tubulidentata over Geological time. - Afrotherian Conservation 4: 6-11

Lehmann, T. 2006b. Distribution of Tubulidentata species and their relationships with early hominids. Biannual meeting of the Palaeontological Society of South Africa, Grahamstown.

Lehmann, T. 2006c. Langebaanweg aardvarks: phylogenetic and palaeobiogeographical implications. - African Natural History 2: 187-188.

Lehmann, T. 2007. Amended taxonomy of the order Tubulidentata (Mammalia, Eutheria). - Annals of the Transvaal Museum 44: 179-196.

Lehmann, T. Phylogeny and systematics of the Orycteropodidae (Mammalia, Tubulidentata). - Zoological Journal of the Linnean Society. In press

Lehmann, T., Likius, A., Mackaye, H. T., Vignaud, P. \& Brunet, M. 2006. A sub-complete fossil aardvark from the Upper Miocene of Chad. - Comptes Rendus Palevol 5: 693-703.

Lehmann, T., Vignaud, P., Likius, A. \& Brunet, M. 2005. A new Orycteropodidae (Mammalia, Tubulidentata) in the Mio-Pliocene of northern Chad. - Zoological Journal of the Linnean Society 143 (1): 109-131.

Lehmann, T., Vignaud, P., Likius, A. \& Brunet, M. 2004. A fossil aardvark (Mammalia, Tubulidentata) from the lower Pliocene of Chad. - African Journal of Earth Science 40: 201-217.

MacInnes, D. G. 1956. Fossil Tubulidentata from East Africa. - Fossil Mammals of Africa, London: British Museum (Natural History) 10: $1-38$.

MacPhee, R. D. E. 1994. Morphology, adaptations, and relationships of Plesiorycteropus, and a diagnosis of a new order of eutherian Mammals. - Bulletin of the American Museum of Natural History 220: $1-214$. 
Made, J. van der. 2003. The aardvark from the Miocene hominoid locality çandir, Turkey. - Courier Forschungs-Institut Senckenberg, Frankfurt 240: 133-147.

McDougall, I. \& Brown, F. H. 2006. Precise 40Ar/39Ar geochronology for the upper Koobi Fora Formation, Turkana Basin, northern Kenya. - Journal of the Geological Society 163: 205-220.

Patterson, B. 1978. Pholidota and Tubulidentata. In Maglio, V. J. \& Cooke, H. B. S. (eds). Evolution of African Mammals. Harvard University Press, Cambridge: pp. 268-278.

Pickford, M. 1975. New fossil Orycteropodidae (Mammalia, Tubulidentata) from East Africa. - Netherlands Journal of Zoology 25 (1): 57-88.

Pickford, M. 2005. Orycteropus (Tubulidentata, Mammalia) from Langebaanweg and Baard's Quarry, Early Pliocene of South Africa. Comptes Rendus Palevol 4: 715-726.
Rook, L. \& Masini, F. 1994. Orycteropus cf. gaudryi (Mammalia, Tubulidentata) from the late Messinian of the Monticino Quarry (Faenza, Italy). - Bullettino dellà Società Paleontologica Italiana 33 (3): 369-374.

Sen, S. 1994. Les gisements de mammifères du Miocène supérieur de Kemiklitepe, Turquie: 5. Rongeurs, Tubulidentés et Chalicothères. - Bulletin du Muséum National d'Histoire Naturelle de Paris 16, 4ème série; section $\mathrm{C}(1)$ : 97-111.

White, T. D., Woldegabriel, G., Asfaw, B., Ambrose, S., Beyene, Y., Bernor, R. L., Boisserie, J.-R., Currie, B., Gilbert, H., Haile-Selassie, Y., Hart, W. K., Hlusko, L. J., Howell, F. C., Kono, R. T., Lehmann, T., Louchart, A., Lovejoy, C. O., Renne, P. R., Saegusa, H., Vrba, E. S., Wesselman, H. \& Suwa, G. 2006. Asa Issie, Aramis and the origin of Australopithecus. - Nature 440: 883889. 
